\title{
Coronary Slow Flow Phenomenon: The Role of New Echo cardiographic Indices
}

\author{
MAGDY M. ABDELSAMEI, M.D.; MOHAMED GOUDA MOHAMED, M.D.; \\ ISLAM M. ABDELMONEM, M.Sc. and AHMED S. ELDAMANHORY, M.D.
}

The Department of Cardiology, Faculty of Medicine, Zagazig University

\begin{abstract}
Background: The Coronary Slow Flow Phenomenon (CSFP) is defined as a delayed distal vessel contrast opacification in the absence of obstructive epicardial coronary artery disease during coronary angiography. There is conflicting data in medical literature regarding the effects of CSFP on the left ventricular functions assessed by conventional echocardiography or tissue Doppler imaging.

Aim of Study: To evaluate whether there is impairement of Global Longitudinal Strain (GLS) of the Left Ventricle (LV) obtained by Speckle Tracking Echocardiography (STE) in patients with CSFP and the role of GLS of the left ventricle in prediction of CSFP.
\end{abstract}

Patients and Methods: Patients with chronic stable angina referred for coronary angiography from February 2015 to Augusts 2017 at the Department of Cardiology, Faculty of Medicine; Zagazig University Hospitals were examined. 31 patients with CSFP and 52 age and sex matched controls without CSFP were enrolled in the study. Diagnosis of CSFP was made by TIMI Frame Count (TFC). GLS of LV was measured by two dimensional (2D) STE in addition to other conventional and tissue Doppler parameters to assess LV diastolic and systolic functions.

Results: LV GLS was lower in CSFP group patients $(-15$ $\pm 2.73)$ compared to control group $(-17.19 \pm 2.54)(p=0.001)$ There was statistically significant negative correlation between mean TFC and LV GLS ( $r=-0.33, p=0.002)$. LVEF by modified Simpson method was lower in CSFP group $(57.77 \pm 5.66 \%)$ compared to control group $(59.29 \pm 3.32 \%)$ but with no statistical significance $(p=0.18)$. Left atrial diameter, LAVI were larger in CSFP group compared to control group $(p<0.05)$ MV E/Ep and TV E/Ep was higher in CSFP group compared to control group $(p<0.001)$. Smoking was the only risk factors that showed statistical significance being more common in CSFP patients $(p=0.003)$ with positive correlation between mean TFC and smoking index $(r=0.28, p=0.002)$.

Conclusion: CSFP impaires LV systolic and diastolic function, RV diastolic function. We found significant negative correlation between mean TFC and GLS of LV.

Correspondence to: Dr. Magdy M. Abdelsamei, The Department of Cardiology, Faculty of Medicine, Zagazig University
Key Words: Coronary slow flow - Global longitudinal strain - Smoking.

\section{Introduction}

THE Coronary Slow Flow Phenomenon (CSFP) is an angiographic clinical entity, characterized by delayed distal vessel opacification in the absence of significant epicardial coronary stenosis [1]. CSFP has direct clinical implications, as it has been linked to clinical manifestations of myocardial ischemia, life-threatening arrhythmias, sudden cardiac death, and recurrent acute coronary syndromes. However, clinical practice tends to underestimate the impact of CSFP due to the yet unknown mechanisms, its relative rarity, and the subsequent difficulties in conducting randomized trials to evaluate different treatment options [2]. Two dimensional (2D) Speckle Tracking Echocardiography (STE) is an emerging technology that measures strain and strain rate by tracking speckles in 2D grayscale echocardiographic images. It is able to measure myocardial motion in any direction irrespective of the direction of the beam, and provides strain in all dimensions; longitudinal, radial, and circumferential [3]. This objective, comprehensive, and noninvasive methodology can detect and assess myocardial diastolic and systolic performance. Abnormalities of strain and strain rate can be found early in the development of many pathophysiologic states, and thus provide a sensitive means for detecting myocardial dysfunction [4]

Aim of the work:

To evaluate whether there is impairement of GLS of the left ventricle obtained by Speckle Tracking Echocardiography (STE) in patients with CSFP and the role of GLS of the left ventricle in prediction of CSPF. 


\section{Patients and Methods}

Patients with chronic stable angina referred for coronary angiography from February 2015 to Augusts 2017 at the Department of Cardiology, Faculty of Medicine; Zagazig University Hospitals were examined. 31 patients with CSFP and 52 ageand sex-matched controls without CSFP were enrolled in the study.

\section{Inclusion criteria:}

All patients with chronic stable angina who underwent cardiac catheterization were recruited.

\section{Exclusion criteria:}

Patients are excluded from the study if one or more of the following criteria are present:

A- Myocardial infarction.

B- Significant coronary artery stenosis.

C- Coronary vasospasm.

D- Coronary ectasia.

E- Uncontrolled hypertension and severe Left Venrtricular Hypertrophy (LVH).

F- Atrial fibrillation and cardiac rhythms other than sinus.

G- Heart failure and cardiomyopathy.

$\mathrm{H}$ - Significant valvular heart disease.

I- Connective tissue disease.

J- Tachycardia, anemia and thyrotoxicosis.

K- Malignancy, renal or hepatic dysfunction.

\section{Complete history taking and examination:}

Thorough history taking for diabetes, hypertension, dyslipidemia, family history of premature $\mathrm{CAD}$, Smoking that was graded according smoking index calculated by number of ciggerates per day multiplied by duration by years [5]. Physical examination with special emphasis on grading of angina pain according Canadian Cardiovascular Society Classification (CCS angina class) [6].

\section{Electrocardiographic examination (ECG):}

Standard 12-lead surface ECG was done for every patient.

\section{Trans-thoracic echocardiography:}

The echocardiographic examination was performed with a $2.5 \mathrm{MHz}$ phased-array transducer and a transthoracic echocardiographic recorder system (Vivid E9 commercial ultrasound scanner with phased-array transducers (M5S-D and 4V-D). Images were taken while the patient is supine or in left lateral position, utilizing 2D, M-mode, Doppler echocardiographic techniques and STE.
We evaluated Left Ventricular End Diastolic Diameter (LVEDD), Left Ventricular End Systolic Diameter (LVESD), ejection fraction and fraction shortening, LV Mass Index (LVMI), Left Atrium Volume Index (LAVI). Doppler recordings were obtained with the pulsed sample volume placed at the tip of the mitral and Tricuspid leaflets from the apical 4-chamber view. Peak early and late velocities, E-wave deceleration time and were measured [7]. From the apical 4-chamber view, the Doppler sample volume was placed at the lateral corner of the mitral annulus and lateral corner of the tricuspid annulus. A Doppler velocity range of -20 to $20 \mathrm{~cm} / \mathrm{s}$ was selected, and the velocities were measured online at a sweep of $100 \mathrm{~mm} / \mathrm{s}$. Peak systolic myocardial velocity (Sm), peak early myocardial velocity $(\mathrm{Em})$, and late myocardial velocity (Am) were measured for the lateral segment and the Em/Am ratio was calculated [8]. Using STE, Dynamic 2D ultrasound images of three cardiac cycles from apical two-, three-, and four chamber views will be acquired using conventional ultrasound, with a frame rate of 57 to 72 frames per second. Endocardial boundary of the left ventricle was delineated manually, after which the software automatically drew the epicardial boundary. The widths of the regions of interest was adjusted manually to match the actual endocardial and epicardial boundaries. Automatic frame-by frame tracking of speckle patterns during the cardiac cycle yielded a measure of strain and strain rate at any part of the myocardium. LV myocardium was divided into six segments in each apical view, and each segment was individually analyzed. By averaging all LV segmental values in all views, LV peak global systolic longitudinal strain (GLS) and was calculated [1].

\section{Laboratory investigations:}

Routine lab: CBC, RFT, LFT, PTT and INR, high sensitivity troponin, cardiac enzymes and random blood sugar level.

\section{Coronary angiography:}

CAG was performed in Zagazig University Hospitals Catheterization laboratories (Cine angiographic equipment: GE Innova: Cine frame: $30 \mathrm{fps}$ ). Selective coronary angiography with standard multiangulated angiographic views was performed through the femoral artery under local anesthesia (2\% Lidocaine) using the Judkins catheters and iopromide (Ultravist) as the contrast agent. The angiograms were recorded on a compact disc in DICOM format. Coronary blood flow was measured quantitatively using the TIMI frame count which was derived from the number of cine-frames recorded from the first 
entrance of contrast to its arrival at the distal end of the left anterior descending artery, circumflex artery, or right coronary artery.

The last frames used for the LAD, Cx and RCA were those in which the dye first entered the mustache segment, the distal bifurcation segment and first branch of the posterolateral artery, respectively. The TIMI frame count of the LAD artery was corrected by dividing the final count by 1.7 . The cut-off values were defined according to the TIMI frame count method of Gibson et al., ( $36 \pm 2.6$ for LAD, 22.2 \pm 4.1 for $\mathrm{Cx}, 20.4 \pm 3.0$ for RCA) [9]

\section{Statistical analysis:}

Data were then imported into Statistical Package for the Social Sciences (SPSS version 16.0) software for analysis. Quantitative data were expressed as means $\pm \mathrm{SD}$ and qualitative data were expressed as absolute frequencies (number) \& relative frequencies (percentage). Differences between means in two parametric groups were compared by Student's $t$-test. Non-parametric data by Mann-Whitney test. Sensitivity, specificity, Positive Predictive Value (PPV), Negative Predictive Value (NPV) were used to plot receiving operative curve. Multivariate Logistic regression analysis was used to detect independent predictor of certain parameter. $p$-value was set at $<0.05$ for significant results $\&$ $<0.001$ for high significant results [10].

\section{Results}

Regarding demographic data and risk factors, there was no significant difference between both groups as regards demographic data and risk factors except for smoking that was significantly more common in group I (CSF patients) $(p<0.05)$ (Table 1).

Table (1): Demographic data and risk factors of both groups.

\begin{tabular}{|c|c|c|c|c|}
\hline & $\begin{array}{l}\text { Group (I) } \\
(\mathrm{n}=31)\end{array}$ & $\begin{array}{l}\text { Group (II) } \\
\quad(\mathrm{n}=52)\end{array}$ & $\begin{array}{c}\text { Test } \\
\text { value }\end{array}$ & $\begin{array}{c}p- \\
\text { value }\end{array}$ \\
\hline $\begin{array}{l}\text { Age (years): } \\
\text { Mean } \pm \mathrm{SD}\end{array}$ & $53.06 \pm 8.86$ & $53.2 \pm 7.41$ & -0.08 & 0.093 \\
\hline $\begin{array}{l}\text { Gender: } \\
\text { Mn }(\%) \\
\text { Fn }(\%)\end{array}$ & $\begin{array}{l}22(71 \%) \\
9(29 \%)\end{array}$ & $\begin{array}{l}26(50 \%) \\
26(50 \%)\end{array}$ & 3.5 & 0.06 \\
\hline $\begin{array}{r}B M I\left(K g / m^{2}\right): \\
\text { Mean } \pm \text { SD }\end{array}$ & $31.58 \pm 6.26$ & $29.98 \pm 3.09$ & 1.32 & 0.19 \\
\hline$H T N: \mathrm{N}(\%)$ & $16(51.6 \%)$ & $33(63.5 \%)$ & 1.12 & 0.28 \\
\hline$D M: \mathrm{N}(\%)$ & $12(38.7 \%)$ & $10(19.2 \%)$ & 3.78 & 0.052 \\
\hline Smoking: N (\%) & $18(58.1 \%)$ & $13(25 \%)$ & 9.07 & 0.003 \\
\hline +ve family history: $\mathrm{N}(\%)$ & $13(41.9 \%)$ & $14(26.9 \%)$ & 1.99 & 0.093 \\
\hline $\begin{array}{l}\text { PCSF : Primary Coronary S } \\
\text { DM : Diabetes. } \\
>0.05: \text { Statistically non-sig } \\
<0.05: \text { Statistically signific }\end{array}$ & $\begin{array}{l}\text { ow Flow. } \\
\text { ificant. } \\
\text { nt. }\end{array}$ & $\begin{array}{ll}\text { I } & : \text { Male } \\
\text { F }: \text { Fem } \\
\text { BMI : Body } \\
\text { HTN : Hype }\end{array}$ & $\begin{array}{l}\text { le. } \\
\text { Mas } \\
\text { rtensi }\end{array}$ & dex. \\
\hline
\end{tabular}

Regarding clinical data, Group I patients presented with higher CCS angina class compared to the control group. There was no significant difference concerning HR, SBP and DBP (Table 2).

Table (2): Clinical data and TFC of both groups.

\begin{tabular}{|c|c|c|c|c|}
\hline & $\begin{array}{c}\text { Group (I) } \\
(\mathrm{n}=31)\end{array}$ & $\begin{array}{c}\text { Group (II) } \\
(\mathrm{n}=52)\end{array}$ & $\begin{array}{c}\text { Test } \\
\text { value }\end{array}$ & $\begin{array}{c}p- \\
\text { value }\end{array}$ \\
\hline \multicolumn{5}{|l|}{ HR bpm: } \\
\hline - Mean $\pm \mathrm{SD}$ & $75.45 \pm 11.91$ & $77.78 \pm 9.38$ & 0.99 & 0.32 \\
\hline \multicolumn{5}{|l|}{ SBP $m m H g:$} \\
\hline - Mean \pm SD & $124.03 \pm 13.8$ & $120.76 \pm 13.73$ & -1.06 & 0.29 \\
\hline \multicolumn{5}{|l|}{ DBP mmHg: } \\
\hline - Mean \pm SD & $79.03 \pm 8.2$ & $79.03 \pm 9.9$ & 0.003 & 0.99 \\
\hline \multicolumn{5}{|l|}{$\operatorname{CCSA} N(\%):$} \\
\hline - Class $2 \mathrm{~N}(\%)$ & $4 \quad(12.9 \%)$ & $20(38.5 \%)$ & 29.24 & 0.052 \\
\hline - Class $3 \mathrm{~N}(\%)$ & $13(41.9 \%)$ & $32(61.5 \%)$ & & 0.04 \\
\hline - Class $4 \mathrm{~N}(\%)$ & $14(45.2 \%)$ & $0(0 \%)$ & & $<0.001$ \\
\hline \multicolumn{5}{|l|}{ TFC: } \\
\hline - $\operatorname{cLAD}($ Mean $\pm \mathrm{SD})$ & $40.04 \pm 1.75$ & $20.29 \pm 1.44$ & 55.62 & $<0.001$ \\
\hline - $\operatorname{LCX}($ Mean $\pm \mathrm{SD})$ & $35.77 \pm 6.18$ & $19.28 \pm 1.39$ & 31.81 & $<0.001$ \\
\hline - RCA (Mean \pm SD) & $33.41 \pm 7.39$ & $19.53 \pm 1.44$ & 31.37 & $<0.001$ \\
\hline - Mean TFC (Mean \pm SD) & $36.4 \pm 3.76$ & $19.72 \pm 0.86$ & 24.29 & $<0.001$ \\
\hline
\end{tabular}

HR : Heart Rate. TFC : TIMI Frame Count.

SBP : Systolic Blood Pressure. >0.05 : Statistically non-significant. DBP : Diastolic Blood Pressure. $<0.05$ : Statistically significant. CCSA class : Canadian cardiovascular society Angina Class.

Regarding echocardiographic findings (Table 3 ), there was significant statistical difference between both groups as regards to LVEDD, Left Atrial Volume Index (LAVI), Left Ventricular Mass Index (LVMI). Left Ventricular Ejection Fraction (LVEF) measured by Simpson,s method was lower in CSFP patients compared to controls (57.77 \pm $5.66 \%)$ vs. $(59.29 \pm 3.32 \%)$ but did not reach statistical significance $(p>0.05)$. Concerning Doppler parameter TV E/A ratio, MV E/Ep and TV E/Ep were significantly higher in CSF group compared to control group.

Regarding LV Global Longitudinal Strain (GLS) by Speckle Tracking imaging, it was significantly lower in group I compared to group II $(-15 \pm 2.73)$ Vs $(17.19 \pm 2.54)(p<0.05)$

Regarding laboratory data, there was no statistical significant difference between the two groups concerning lipid profile, platelet count $(p>0.05)$ while there was statistical significant difference regarding haemoglobin level, haematocrit value ( $p$ $<0.05)$ and highly significant difference regarding White Blood Cells, mean platelet volume $(p<0.001)$ (Table 5). 
Table (3): Echocardiographic data of both groups.

\begin{tabular}{|c|c|c|c|c|c|}
\hline & & $\begin{array}{c}\text { Group (I) } \\
(\mathrm{n}=31)\end{array}$ & $\begin{array}{c}\text { Group (II) } \\
(\mathrm{n}=52)\end{array}$ & $\begin{array}{c}\text { Test } \\
\text { value }\end{array}$ & $\begin{array}{c}p- \\
\text { value }\end{array}$ \\
\hline \multicolumn{2}{|l|}{$\begin{array}{l}\cdot \text { - LVEDD mm: } \\
\text { Mean } \pm \text { SD }\end{array}$} & $52.10 \pm 5.35$ & $49.38 \pm 3.97$ & 2.63 & 0.01 \\
\hline \multicolumn{2}{|l|}{$\begin{array}{r}\text { - LVESD mm: } \\
\text { Mean } \pm \mathrm{SD}\end{array}$} & $32.84 \pm 6.89$ & $31.33 \pm 2.35$ & 1.18 & 0.24 \\
\hline \multicolumn{2}{|c|}{$\begin{array}{l}\text { - LVEF M-mode \%: } \\
\text { Mean } \pm \text { SD }\end{array}$} & $58.93 \pm 5.28$ & $63.05 \pm 4.96$ & 0.8 & 0.01 \\
\hline \multicolumn{2}{|c|}{$\begin{array}{l}\text { - LVEF Simpsons \%: } \\
\text { Mean } \pm \text { SD }\end{array}$} & $57.77 \pm 5.66$ & $59.29 \pm 3.32$ & -1.35 & 0.18 \\
\hline \multicolumn{2}{|c|}{$\begin{array}{l}\text { - } L A V I m l / m^{2} \\
\text { Mean } \pm \mathrm{SD}\end{array}$} & $32.35 \pm 3.22$ & $29.96 \pm 4.17$ & 2.92 & 0.005 \\
\hline \multicolumn{2}{|c|}{$\begin{array}{l}\text { - } L V M I \text { in } \mathrm{gm} / \mathrm{m}^{2} \text { : } \\
\text { Mean } \pm \mathrm{SD}\end{array}$} & $113.54 \pm 10.99$ & $9 \quad 105.90 \pm 10.87$ & 3.08 & 0.003 \\
\hline \multicolumn{2}{|c|}{$\begin{array}{l}\cdot M V \text { E/A ratio: } \\
\text { Mean } \pm \mathrm{SD}\end{array}$} & $0.91 \pm 0.42$ & $0.80 \pm 0.17$ & -3.51 & 0.11 \\
\hline \multicolumn{2}{|l|}{$\begin{array}{l}\text { - TV E/A ratio: } \\
\text { Mean } \pm \mathrm{SD}\end{array}$} & $0.93 \pm 0.28$ & $0.83 \pm 0.07$ & 2.33 & 0.02 \\
\hline \multirow{3}{*}{\multicolumn{2}{|c|}{$\begin{array}{l}\text { - } M V E / E p: \\
\text { Mean } \pm \mathrm{SD} \\
\cdot T V E / E p: \\
\text { Mean } \pm \mathrm{SD} \\
\cdot \text { GLS: Mean } \pm \mathrm{SD}\end{array}$}} & $11.02 \pm 3.35$ & $7.83 \pm 1.81$ & 5.61 & 0.000 \\
\hline & & $9.62 \pm 2.37$ & $7.03 \pm 1.24$ & 6.51 & 0.000 \\
\hline & & $-15 \pm 2.73$ & $-17.19 \pm 2.54$ & 3.63 & 0.001 \\
\hline \multicolumn{6}{|c|}{ 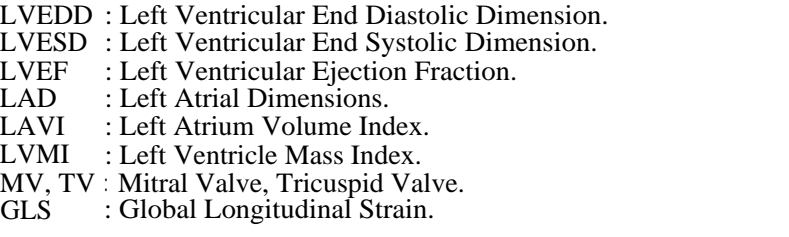 } \\
\hline \multicolumn{6}{|c|}{ Table (4): Lipid profile of both groups. } \\
\hline & & $\begin{array}{l}\operatorname{roup}(\mathrm{I}) \\
(\mathrm{n}=31)\end{array}$ & $\begin{array}{l}\text { Group (II) } \\
(\mathrm{n}=52)\end{array}$ & $\begin{array}{c}\text { Test } \\
\text { value }\end{array}$ & $\begin{array}{c}p- \\
\text { value }\end{array}$ \\
\hline $\begin{array}{l}T C(m g / d l): \\
\quad \text { Mean } \pm \mathrm{SD}\end{array}$ & 229 & $51 \pm 31.17$ & $238.57 \pm 32.99$ & 1.23 & 0.22 \\
\hline $\begin{array}{l}T G(m g / d l): \\
\quad \text { Mean } \pm \text { SD }\end{array}$ & 101 & $.96 \pm 20.91$ & $97.17 \pm 14.47$ & -1.23 & 0.22 \\
\hline $\begin{array}{l}L D L(m g / d l): \\
\quad \text { Mean } \pm \mathrm{SD}\end{array}$ & 141 & $.96 \pm 26.93$ & $150.97 \pm 22.09$ & 1.59 & 0.11 \\
\hline $\begin{array}{l}H D L(m g / d l): \\
\quad \text { Mean } \pm \text { SD }\end{array}$ & 42.1 & $6 \pm 1.98$ & $42.36 \pm 2.73$ & 0.36 & 0.71 \\
\hline
\end{tabular}

Table (5): Blood picture of both groups.

\begin{tabular}{|c|c|c|c|c|}
\hline & $\begin{array}{l}\text { Group (I) } \\
(\mathrm{n}=31)\end{array}$ & $\begin{array}{l}\text { Group (II) } \\
(\mathrm{n}=52)\end{array}$ & $\begin{array}{c}\text { Test } \\
\text { value }\end{array}$ & $\begin{array}{c}p- \\
\text { value }\end{array}$ \\
\hline $\begin{array}{l}\text { - } W B C(X 1000 / \mathrm{cmm}): \\
\text { Mean } \pm \mathrm{SD}\end{array}$ & $8.61 \pm 1.75$ & $6.79 \pm 1.53$ & 4.94 & 0.000 \\
\hline $\begin{array}{r}H G B(g / d l): \\
\text { Mean } \pm \mathrm{SD}\end{array}$ & $12.68 \pm 1.08$ & $12.12 \pm 0.99$ & 2.40 & 0.01 \\
\hline $\begin{array}{l}-H C T(\%): \\
\text { Mean } \pm \text { SD }\end{array}$ & $41.26 \pm 4.11$ & $39.11 \pm 2.09$ & 2.70 & 0.01 \\
\hline $\begin{array}{l}\text { - } P L T(X 1000 / \mathrm{cmm}): \\
\text { Mean } \pm \mathrm{SD}\end{array}$ & $258.41 \pm 28.46$ & $273.71 \pm 53.14$ & -1.48 & 0.14 \\
\hline $\begin{array}{l}-M P V(f L): \\
\text { Mean } \pm \mathrm{SD}\end{array}$ & $9.36 \pm 1.83$ & $7.70 \pm 1.16$ & 4.51 & 0.000 \\
\hline $\begin{array}{l}\text { WBC : White Blood } \\
\text { HGB : Hemoglobin. } \\
\text { HCT : Hematocrit. }\end{array}$ & $\begin{array}{l}\text { PLT } \\
\text { MPV }\end{array}$ & $\begin{array}{l}\text { : Platelets. } \\
\text { : Mean Platel }\end{array}$ & t Vol & \\
\hline
\end{tabular}

There was significant positive correlation between TIMI Frame Count (TFC) and smoking index Fig. (2).

There was significant negative correlation between TFC and GLS $(r=-0.33, p<0.05)$, and significant positive correlation between TFC each of the following; LAVI ( $r=0.22, p<0.05)$, WBCs $(r=0.49, p<0.001)$, HCT value $(r=0.27, p<0.05)$ MPV $(r=0.33, p<0.001)$ and smoking index $(r=0.28$, $p<0.05)$ Figs. (1-4).

Regarding Receiver Operator Characteristic (ROC) curves for different echocardiograpic and laboratory parameters to obtain cut off values to predict CSFP.

The ROC curve for LV GLS showed areas under the curve of 0.72 and a $p$-value $>0.05$. A cut-off value of $\leq-15.85 \%$ for LV GLS had a sensitivity of $71 \%$ and specificity of $75 \%$ for the diagnosis of CSFP Fig. (5).

The ROC curve for smoking index showed areas under the curve of 0.65 and a $p$-value $>0.05$. A cut-off value of $\geq 820$ had a sensitivity of $97 \%$ and specificity of $81 \%$ for the diagnosis of CSFP.

The ROC curve for WBCs showed areas under the curve of 0.78 and a $p$-value $>0.001$. A cut-off value $\geq 7.5 \times 1000 / \mathrm{cmm}$ for WBCs had a sensitivity of $71 \%$ and specificity of $77.3 \%$ for the diagnosis of CSFP.

The ROC curve for MPV showed areas under the curve of 0.76 and a $p$-value $>0.001$. A cut-off value of $\geq 7.8 \mathrm{fL} \%$ for MPV had a sensitivity of $77.4 \%$ and specificity of $65.4 \%$ for the diagnosis of CSFP.

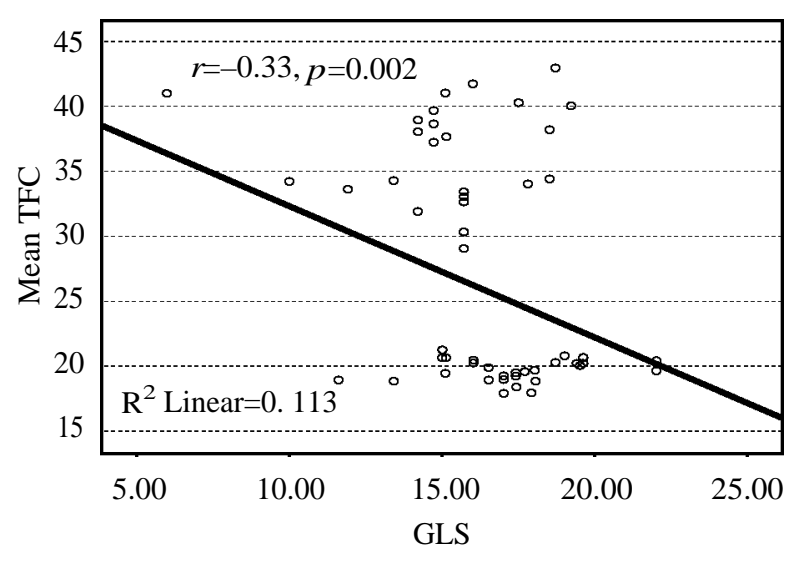

Fig. (1): Shows significant negative correlation between mean TFC and LV GLS using spearman correlation coefficient with $(r=-0.33)$ and $(p<0.05)$. 


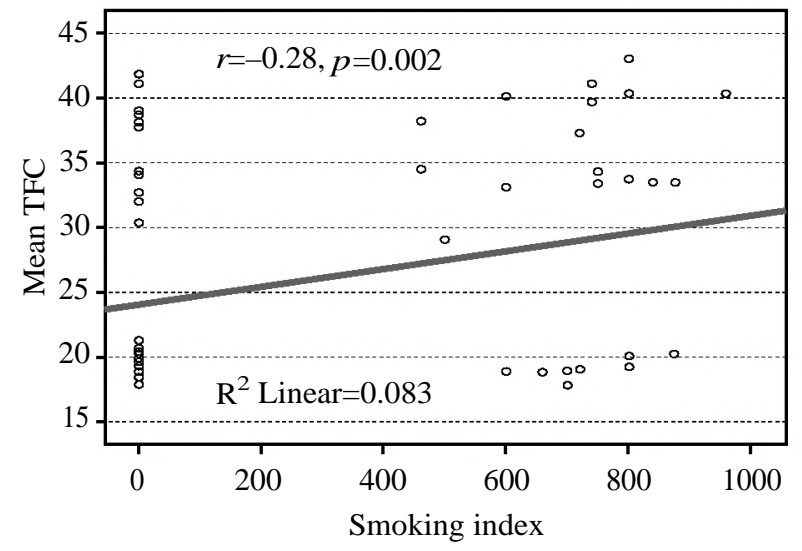

Fig. (2): Shows significant positive correlation between mean TFC and smoking index using spearman correlation coefficient with $(r=0.28)$ and $(p<0.05)$.

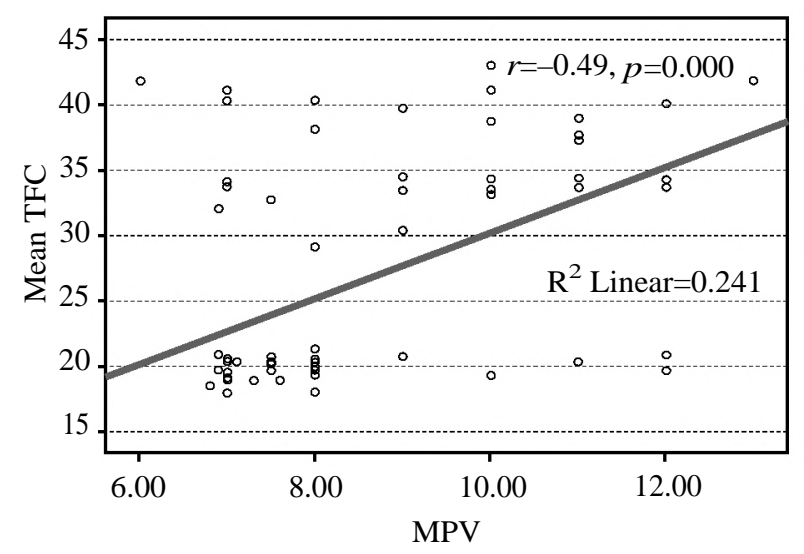

Fig. (3): Shows significant positive correlation between mean TFC and MPV using spearman correlation coefficient with $(r=0.49)$ and $(p<0.001)$.

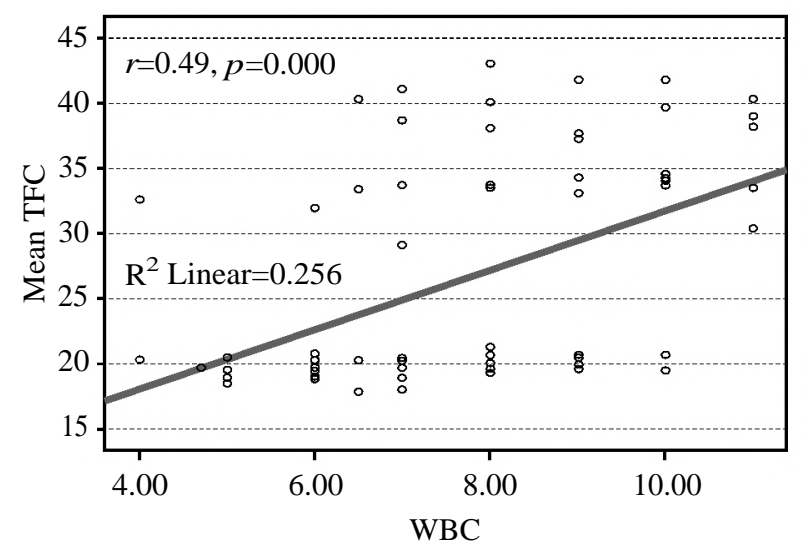

Fig. (4): Shows significant positive correlation between mean TFC and WBCs using spearman correlation coefficient with $(r=0.49)$ and $(p<0.001)$.

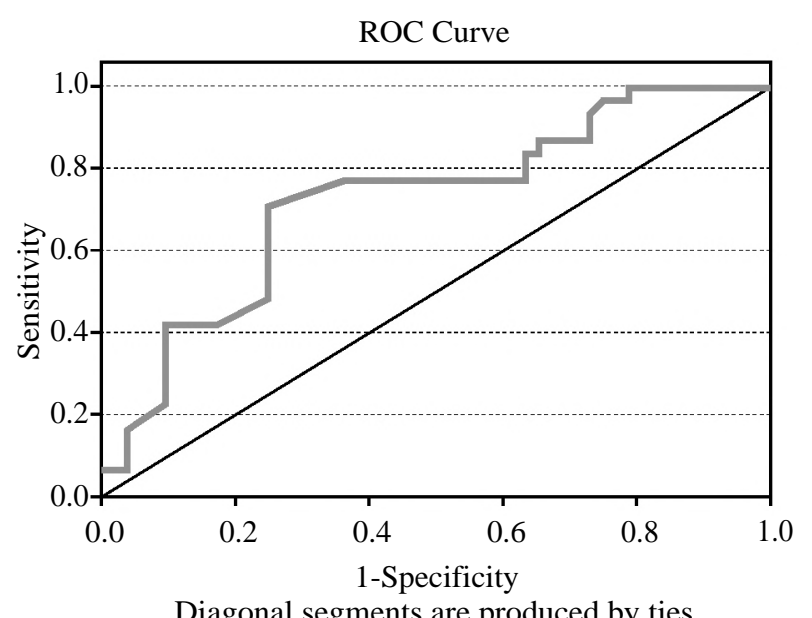

Diagonal segments are produced by ties

Fig. (5): ROC curve for LV GLS showing sensitivity of $71 \%$ and specificity of $75 \%$ at a cut off value of $-15.85 \%$ (AUC at $95 \% \mathrm{CI}=0.72(0.61-0.83)$ ).

Regarding multivariate logistic regression analysis, WBCs was the most independent predictor of CSFP ( $p<0.05$, OR: 2.69$)$, followed by MPV ( $p$ $<0.05$, OR: 2.32$)$, LAVI $(p<0.05$, OR: 1.48$)$, then LV GLS ( $p<0.05$, OR: 1.45) (Table 6).

Table (6): Stepwise regression analysis of factors predicting PCSF.

\begin{tabular}{llllll}
\hline & $\mathrm{R}$ & S.E. & Wald & $p$-value & OR \\
\hline LV GLS & 0.37 & 0.17 & 4.48 & 0.03 & 1.45 \\
MPV & 0.84 & 0.27 & 9.69 & 0.002 & 2.32 \\
WBCs & .991 & .330 & 9.035 & 0.003 & 2.69 \\
Smoking & $-2.213-$ & 1.035 & 4.569 & 0.03 & 0.10 \\
LAVI & .393 & .153 & 6.586 & 0.01 & 1.48 \\
LVMI & .012 & .041 & .092 & 0.76 & 1.01 \\
HGB & .400 & .404 & .982 & 0.32 & 1.49 \\
\hline
\end{tabular}

WBC: White Blood Cells. LAVI : Left Atrium Volume Index. HGB : Hemoglobin. $\quad$ LVMI : LV Mass Index.

HCT : Hematocrit. GLS : Global Longitudinal Strain PLT : Platelets. OR : Odds Ratio.

MPV : Mean Platelet Volume.

\section{Discussion}

CSFP is an angiographic diagnosis characterized by a slow rate of flow of dye in the normal or nearnormal epicardial coronary arteries [9]

CSFP has direct clinical implications, as it has been linked to clinical manifestations of myocardial ischemia, life-threatening arrhythmias, sudden cardiac death, and recurrent acute coronary syndromes [11] 
The precise etiology and pathophysiologic mechanism of CSFP are not sufficiently clear. Previous studies have postulated several mechanisms, such as endothelial and microvascular dysfunction, early stage coronary atherosclerosis, rheologic abnormalities, a systemic inflammatory state, and metabolic perturbations [12].

However, clinical practice tends to underestimate the impact of CSFP due to the yet unknown mechanisms, its relative rarity, and the subsequent difficulties in conducting randomized trials to evaluate different treatment options [2].

Our study was conducted in Zagazig University Hospitals to assess the impact of CSFP on left ventricular function and to assess the role of new echocardiographic indices in prediction of CSFP. Patients were divided into two groups; Group I (CSFP) 31 pateints and Group II (normal coronary angiography), 52 patients.

The present study showed no statistically significant difference between both groups the age, gender, Body Mass Index (BMI), hypertension, diabetis mellitus. This was concordant with Elsherbiny 2012 [13], Altunkas et al., 2014 [14] and Wang et al., 2015 [1] and discordant with Hawkins B et al., 2011 [15] where they found patients with CSFP were more males and had higher (BMI). This might be contributed to the nature of the population studied with certain differences between the Japanese people and the Egyptians. This also was discordant with Yilmaz $\mathrm{H}$ et al., 2010 [16] and Gunes Y et al., 2011 [17] where they found patients with PCSF had higher BMI this might be due to increased the incidence of obesity in the Egyptian population.

Regarding smoking, in our study CSF phenomenon was more common in smokers with statistical significant difference. There was strong positive correlation between smoking index and mean TFC. This was concordant with Selcuk et al., 2010 [18] and Li et al., 2014 [19]. Also Arbel et al., 2012 [20] reported that smoking was found to be the strongest predictor of the SCFP.

In discordance with our findings, Gunes et al., 2009 [21] and Altunkas et al., 2014 [14] did not find statistical significant difference regarding smoking between CSFP patients and controls. This might be because both studies were conducted in Turkey, which previously was a country with the highest smoking rates in the world until 2009 [22]

In our study, there was no statistical difference between both groups regarding the heart rate and blood pressure (systolic and diastolic) this was in agreement with Elsherbiny 2012 [13], Altunkas et al., 2014 [14], Li et al., 2014 [19] and Wang et al., 2015 [1]

Regarding the Canadian Cardiovascular Society Class Angina, our patients with CSFP had presented with higher classes. This was in agreement with Bencze et al., 2006 [23] who reported that about one third of CSFP patients presented with higher CCS Angina class compared to $9 \%$ of patients without CSF.

2D-STE is an emerging technology that measures strain and strain rate by tracking speckles in 2D grayscale echocardiographic images. It is able to measure myocardial motion in any direction irrespective of the direction of the beam, and provides strain in all dimensions; longitudinal, radial, and circumferential [3].

This objective, comprehensive, and noninvasive methodology can detect and assess myocardial diastolic and systolic performance. Abnormalities of strain and strain rate can be found early in the development of many pathophysiologic states, and thus provide a sensitive means for detecting myocardial dysfunction [4]

We measured GLS of left ventricle segments to evaluate left ventricular functions in patients with CSFP versus patients with normal coronary angiography.

We found that GLS was lower in CSFP group patients $(-15 \pm 2.73)$ compared to control group $(-17.19 \pm 2.54)$ with statistical significance $(p<0.05)$. This was concordant with Wang et al., 2015 [1].

We found negative correlation between mean TIMI frame count and GLS ( $r=-0.33, p<0.05)$. Wang et al., 2015 [1] obseved negative correlation between mean TIMI frame count and peak longituidinal systolic strain rate.

On the contrary, Narimani et al., 2016 [24] found that there were no statistically significant differences between the groups regarding the 2D speckletracking derived longitudinal systolic strain.

Gulel et al., 2015 [25] did not observe significant differences between the groups in terms of longitudinal deformation parameters, but they found statistical significant differences in terms of circumferential deformation parameters. They explained this results by the finding of Bansal et al., 2008 [26] who observed that the discriminative power for the detection of regional myocardial 
abnormality was highest for circumferential strain with automated function imaging.

The present study constructed ROC curves to pedict CSFP and determined optimal cut off value $(\leq-18.85)$ for GLS with $71 \%$ sensitivity and $75 \%$ specificity.

As regards to LVEF measured by modified Simpson's method, it was lower in CSFP group patients $(57.77 \pm 5.66 \%)$ compared to control group $(59.29 \pm 3.32 \%)$ but did not reach statistical significance $(p<0.05)$. Our results were concordant with Altunkas et al., 2014 [14] , Y. Li et al., 2014 [19], Wang et al., 2015 [1].

LV diastolic function disorder is the cardiac pathology with the earliest onset in coronary slow flow [14]. In our study, conventional Doppler parameters as MV E/A ratio, there was no significant difference between both groups, however by using Tissue Doppler parameters as MV E/Ep there was statistical significant difference between the two groups. A study has shown that TDE parameters are not affected by preload and heart rate, like conventional Doppler, and thus yield more accurate results [27].

Our results were concordant with Altunkas et al., 2014 [14] who demonstarated LV diastolic dysfunction in CSFP patients using tissue Doppler parameters, but not by conventional Doppler parameters.

Baykan et al., 2009 [28] demonstrated that both LV systolic and diastolic functions were impaired in patients with CSFP.

Tanriverdi et al., 2010 [29] found that LV diastolic function deteriorated in patients with SCFP using conventional Doppler echocardiography, while Zencir et al., 2013 [30] observed that LV systolic and diastolic function were preserved in patients with SCF when evaluated using conventional and tissue Doppler echocardiography.

In the present study, CSFP group patients had greater LA diameter, LAVI compared to the control group with stastistical significant difference. Wang et al., 2016 [31] also observed larger LA diameters and LAVI in PCSF patients but without stastistical significance. Wang et al., 2015 [1], Altunkas et al., 2014 [14] observed larger LA diameters but without stastistical significance.

Regarding RV diastolic function, our study revealed that CSFP impaired RV diastolic function in the term of TV E/A ratio and TV E/e' that showed statistical significant difference. This finding was concordant with Wang et al., 2015 [1]

However, Altunkas et al., 2014 [14] observed no statistically significant difference between CSFP patients and controls regarding RV functions. Also Hosseinsabet A et al., 2016 [32] showed no statistically significant differences between the 2 groups regarding tricuspid pulsed-wave, RV tissue Doppler, and RV deformation indices. This could be explained by lower mean TFCs, different sample size and design as the two aforementioned studies included 1:1 patient: Control matching design unlike our study.

In our study, there was no statistical significant difference regarding the lipid panel in either groups. This was in agreement with Ari H. et al., 2010 [33] and Gunes Y et al., 2011 [17] and disagree with Tanriverdi $\mathrm{H}$ et al., 2010 [29] and Yilmaz $\mathrm{H}$ et al., 2010 [16] this might be due to the increased BMI in both groups in our study with abnormal lipid panels in both.

In our study, patients with CSFP had higher levels of WBCs, HCT and MPV compared to patients in the control group. This was in agreement with Nurkalem Z et al., 2008 [34] who showed higher MPV in PCSF group and Yaron A et al., 2009 [35] who showed higher HCT level in CSFP group. Both indicate increased blood viscosity in those patients with CSFP.

Soylu K et al., 2014 [36] found that there was no significant difference regarding WBCs, MPV while HB and HCT value were significantly higher in PCSF patients. Sanati H et al., 2016 [37] and Li. Y et al., 2016 [38] observed no statistical significant difference regarding WBCs, platelets, Haemoglobin, Haematocrit level between PCSF pateients and controls.

Platelets play critical roles in inflammation, thrombosis, and cardiovascular physiopathology. Additionally, increased MPV is associated with acute coronary syndrome, carotid artery disease, sepsis, deep vein thrombosis, pulmonary embolism, and coronary collateral vessels [39].

It is known that platelets having dense granules are more active biochemically, functionally and metabolically and are a risk factor for developing coronary thrombosis. Large platelets secrete high levels of prothrombogenic thromboxane A2, serotonin, beta thromboglobulin, and procoagulant membrane proteins like P-selectin and glycoprotein IIIa. In addition they are less sensitive to inhibitory effects of prostacycline on aggregation and secretion than small platelets [34] 
Further studies are needed to evaluate the usefulness of those echocardiographic and laboratory parameters in follow-up and monitoring efficacy of treatment and prognosis of CSF patients.

\section{Clinical implication:}

2D Speckle tracking Echocardiography should be used on a wider scale for evalution of ventricular functions, avoiding the fallacies of conventional Doppler and TDI parameters. It can early detect subclinical ventricular dysfunction. It can be used for pediction of CSFP.

Further studies should be conducted on CSFP to evaluate adequate treatment, prognosis and follow-up of those patients.

\section{Study limitations:}

- The results were obtained from a single medical center (Zagazig University Hospitals).

- Sample size was relatively small.

- Clear delineation of endocardial borders was difficult in some patients especially obese patients or pateints with causes of poor echo window.

- Lack of follow-up of the patients to evaluate the efficacy of treatment and prognosis of CSF.

\section{Conclusion:}

LV systolic and diastolic functions were impaired in patients with CSFP. CSFP also affected $\mathrm{RV}$ diastolic function. STE derived parameters as LV GLS have a role in detection of ventricular dysfunction in CSF patients and in prediction of CSFP.

\section{References}

1- WANG Y., MA C., ZHANG Y., GUAN Z., LIU S., LI Y., et al.: Assessment of Left and Right Ventricular Diastolic and Systolic Functions Using Two-Dimensional SpeckleTracking Echocardiography in Patients with Coronary Slow-Flow Phenomenon. PLoS ONE, 10 (2): e0117979, 2015.

2- WANG X. and NIE S.: The Coronary Slow Flow phenomenon: Characteristics, mechanisms and implications. Cardiovasc. Diagn. Ther., 1: 37-43, 2011.

3- MARECHAUX S.: Speckle-tracking strain echocardiography: Any place in routine daily practice in 2014? Arch. Cardiovasc. Dis., 106: 629-34, 2013.

4- MOR-AVI V., LANG R.M., BADANO L.P., BELOHLAVEK M., CARDIM N.M., et al.: Current and evolving echocardiographic techniques for the quantitative evaluation of cardiac mechanics: ASE/EAE consensus statement on methodology and indications endorsed by the Japanese Society of Echocardiography. Eur. J. Echocardiogr., 12: 167-205, 2011

5- JINDAL S.K. and MALIK S.K.: Smoking Index-A Measure To Quantify Cumulative Smoking Exposure. Lung
India 1988, 6: 195-96. Volume: 6 | Issue Number: 4 | Page: 195-6, 1988.

6- CAMPEAU LUCIEN: Grading of angina pectoris. Circulation, 54: 5223, 1976.

7- LANG R.M., BADANO L.P., MOR-AVI V., et al.: Recommendations for cardiac chamber quantification by echocardiography in adults: An update from the American Society of Echocardiography and the European Association of Cardiovascular Imaging. J. Am. Soc. Echocardiogr., Jan., 28 (1): 1-39.e14, 2015.

8- NAGUEH S.F., APPLETON C.P., GILLEBERT T.C., et al.: Recommendations for the evaluation of left ventricular diastolic function by echocardiography. Eur. J. Echocardiogr., 10: 165-93, 2009.

9- GIBSON C.M., CANNON C.P., DALEY W.L., DODGE J.T. Jr, ALEXANDER B. Jr., et al.: TIMI frame count: A quantitative method of assessing coronary artery flow. Circulation, 93: 879-88, 1996.

10- DEAN J.A. and COULABIER D.: A word processing database and statistic program for epidemiology on microcomputer CDC, Atlanta, Gorgia, USA, 2000.

11- TAMBE A.A., DEMANY M.A., ZIMMERMAN H.A., MASCARENHAS E.: Angina pectoris and slow flow velocity of dye in coronary arteries, a new angiographic finding. Am. Heart J., 84: 66-71, 1972.

12- MANGIERI E., MACCHIARELLI G., CIAVOLELLA M., BARILLA F., AVELLA A., et al.: Slow coronary flow: Clinical and histopathological features in patients with otherwise normal epicardial coronary arteries. Cathet. Cardiovasc. Diagn., 37: 375-81, 1996.

13- ELSHERBINY I.A.: Left ventricular function and exercise capacity in patients with slow coronary flow. Echocardiography, 29: 158-64, 2012.

14- ALTUNKAS F., KOC F., CEYHAN K., CELIK A., KADI H., et al.: The effect of slow coronary flow on right and left ventricular performance. Med. Princ Pract., 23: 349, 2014.

15- HAWKINS B., STAVRAKIS S., ROUSAN T., et al.: Coronary Slow Flow- Prevelance and clinical correlation. Circ. J., 76 (4): 936-42, 2012.

16- YILMAZ M., ERDEM A., YONTAR O., et al.: Relationship between $\mathrm{HbA} 1 \mathrm{c}$ and coronary flow rate in patients with type 2 diabetes mellitus and angiographically normal coronary arteries. Türk. Kardiyol. Dern. Ar ș., 38 (6): 405 $10,2010$.

17- GÜNES Y., GUMRUKCOUGLU H., AKDAG S., et al.: Vascular endothelial function in patients with coronary slow flow and the effects of nebivolol. Arq. Bras. Cardiol., 97 (4): 275-80, 2011

18- SELCUK H., MADEN O., SELCUK M., et al.: Documentation of Impaired coronary blood flow in chronic obstructive pulmonary disease patients. Circ. J., 74: 346-52, 2010.

19- LI Y., WANG Y., JIA D., et al.: Assessment of risk factors and left ventricular function in patients with slow coronary flow Heart Vessels, 31: 288, 2016.

20- ARBEL Y., RIND E., BANAI S., HALKIN A., BERLINER S., HERZ I., et al.: Prevalence and predictors of 
slow flow in angiographically normal coronary arteries Clin. Hemorheol. Microcirc., 52 (1): 5-14, 2012.

21- GUNES Y., TUNCER M., GUNTEKIN U., et al.: The effects of nebivolol on $\mathrm{P}$ wave duration and dispersion in patients with coronary slow flow. Anadolu Kardiyol. Derg., 9: 290-5, 2009.

22- McGONGAL M.: Country with one of the highest smoking rates in the world goes smokefree: Michigan, continues to delay. The conservative media; liberalmedianot. blogspot, 2009.

23- BENCZE J., KISS R.G., TOTH-ZSAMBOKI E., et al.: Characterisation of coronary $\mathrm{X}$ syndrome subtypes identified by coronary blood flow velocity. Eur. Heart J., 27: 349, 2006

24- SIMA NARIMANI, ALI HOSSEINSABET and HAMIDREZA POURHOSSEINI: Effect of Coronary Slow Flow on the Longitudinal Left Ventricular Function Assessed by 2-Dimensional Speckle-Tracking Echocardiography. J. Ultrasound. Med., Apr., 35 (4): 723-9, 2016.

25- GULEL O., AKCAY M., SOYLU K., AKSAN G., YUKSEL S., ZENGIN H., MERIC M. and SAHIN M.: Left Ventricular Myocardial Deformation Parameters Are Affected by Coronary Slow Flow Phenomenon: A Study of Speckle Tracking Echocardiography. Echocardiography (Mount Kisco, N.Y.).33. 10.1111/echo.13146, 2015.

26- BANSAL M., CHO G.Y., CHAN J., et al.: Feasibility and accuracy of different techniques of two-dimensional speckle based strain and validation with harmonic phase magnetic resonance imaging. J. Am. Soc. Echocardiogr., 21: 1318-25, 2008

27- OZDEMIR K., BALCI S., DUZENLI M.A., et al.: Effect of preload and heart rate on the Doppler and tissue Doppler-derived myocardial performance index. Clin. Cardiol., 30: 342-8, 2007.

28- BAYKAN M., BAYKAN E.C., TURAN S., GEDIKLI O., KAPLAN S., et al.: Assessment of left ventricular function and Tei index by tissue Doppler imaging in patients with slow coronary flow. Echocardiography, 26: 1167-72, 2009.

29- TANRIVERDI H., EVRENGUL H., KILIC D., et al.: Aortic pressures, stiffness and left ventricular function in coronary slow flow phenomenon. Cardiology, 116: 261-7, 2010.
30- ZENCIR C., CETIN M., GUNGOR H., KARAMAN K., AKGULLU C., ERYILMAZ U. and AVCIL M.: Evaluation of left ventricular systolic and diastolic functions in patients with coronary slow flow phenomenon. Turk. Kardiyol. Dern. Ars., 41: 691-6, 2013.

31- WANG Y., ZHANG Y., MA C., GUAN Z., LIU S., ZHANG W., et al.: Evaluation of left and right atrial function in patients with coronary slow-flow phenomenon using twodimensional speckle tracking echocardiography. Echocardiography, 33: 871-80, 2016.

32- ALI HOSSEINSABET, SHIMA YARMOHAMAD, SIMA NARIMANI and NAZANIN AMINI-FARSHIDMEHR: Right ventricular function in coronary slow flow: A twodimensional speckle-tracking echocardiographic study. Turk. Kardiyol. Dern. Ars., 44 (6): 466-73, 2016.

33- ARI H., ARI S., ERDOGAN E., et al.: The effect of endothelial dysfunction and inflammation on slow coronary flow. Turk. Kardiyol. Dern. Ars., 38 (5): 327-33, 2010.

34- NURKALEM Z., GORGULU S., USLU N., et al.: Longitudinal left ventricular systolic function is impaired in patients with coronary slow flow. Int. J. Cardiovasc. Imaging, 25: 25-32, 2009.

35- YARON A., EFRAT R., AMIR H., et al.: Determinants of slow flow in patients with normal coronary arteries. TAPAS. www.e-med.co.il/emed/new/usersite/pre sentation, 2009.

36- SOYLU K., GULEL O. and YUCEL H.: The effect of blood cell count on coronary flow in patients with coronary slow flow phenomenon. Pakistan J. Med. Sci., 30: 936$41,2014$.

37- SANATI H., KIANI R., SHAKERIAN F., et al.: Coronary Slow Flow Phenomenon Clinical Findings and Predictors. Research in Cardiovascular Medicine, 5 (1): e30296, 2016.

38- LI Y., WANG Y., JIA D., et al.: Assessment of risk factors and left ventricular function in patients with slow coronary flow Heart Vessels, 31: 288, 2016.

39- DURAN M., GUNEBAKMAZ O., UYSAL O.K., et al.: The relation between mean platelet volume and coronary collateralvessels in patients with acute coronary syndromes. J. Cardiol., 61: 295-8, 2013. 


\section{ظاهرة التدفق البطئ بالشرايين التاجية،

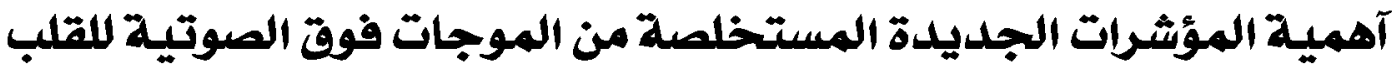

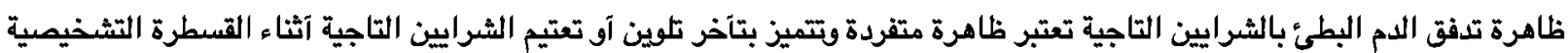

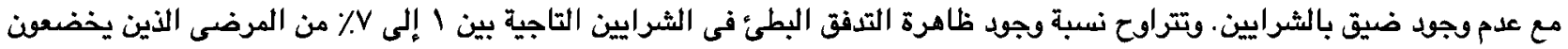

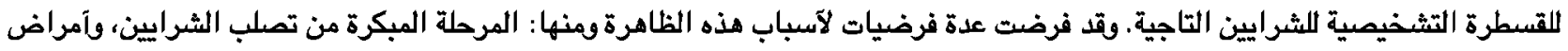

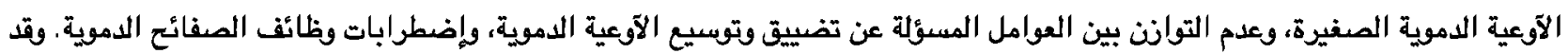

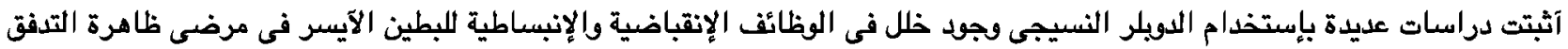

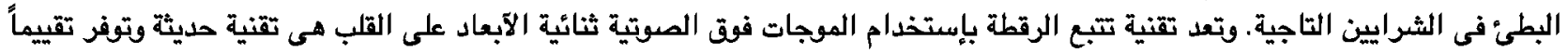

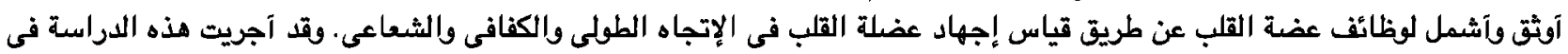

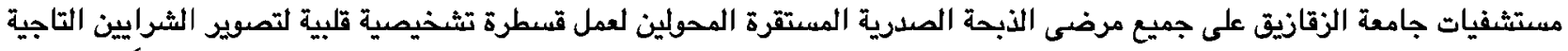

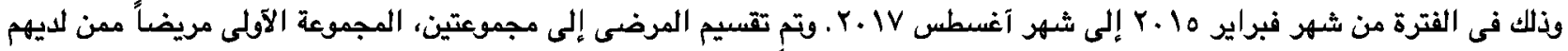

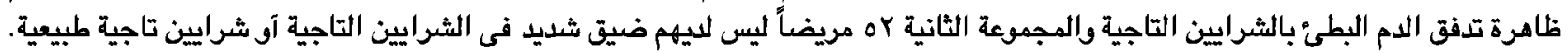

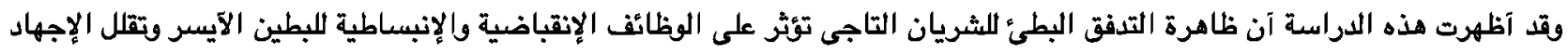

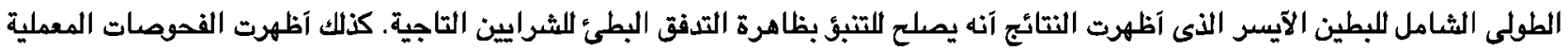

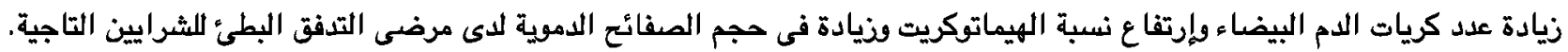

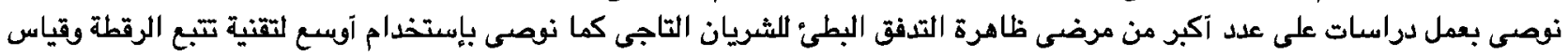

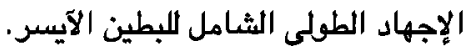

